\title{
Investigation on the Present Situation of Bai Nationality Pottery Thought in Fengyi town Jingtian Village - A Case Study of Young People
}

\author{
Jun Lai, Xiaowang Su \\ Jingdezhen Ceramic Institute, Jingdezhen, Jiangxi, 333000, China \\ Yunnan Arts University, Kunming, Yunnan, 650000, China
}

\begin{abstract}
Dali Fengyi Town, Dali Prefecture, Yunnan Province, is located at the southern end of Dali City, which belongs to Dongshan Village Committee of Fengyi Town. On the slopes after the mountain called Daqing, there are ethnic minority handmade pottery-producing areas, where the Tang Dynasty kiln firing method has been burned for more than 600 years of history. Now there are six kilns in the use, it is a rare dragon kiln gathering area. In 2015, the existing six local Bai craftsmen such as Yang Shaohua and foreign youth Zhang Jiao, a total of two US-made 6 burned earth pottery, baked tea cans products, pickles altar, pipe, water lamp, tea, Jugs and other 30 kinds of products, the collision of two generations of thought makes handicrafts inheritance problems with new possibilities.
\end{abstract}

Keywords: pottery, sharing, simple life aesthetics

\section{The collision of the "biography" and the collision of the "commitment"}

A town of Dali Autonomous Prefecture in Yunnan Province known as "Zhaozhou", "Zhao County", in 1913 changed its name to Fung Yee County. In 1983 the city of Dali, for the municipal area, in 1987 renamed Fengyi town, and evolution so far, has a long history. Recently, some netizens said that in Fengli 
Town, Dali City, the village has a tradition of purely hand-made earth pottery. The process follows the Tang Dynasty kiln method, from the embryo, glaze to firing, each step by hand. However, today, this craft is facing the situation of lost. January 22, 2013, "Yunnan Information Daily" Fengyi town of King Tin village pottery craft of this report, sparked people to respect the village of traditional handicraft thinking, worry technology lost.

6 interviews before and after the two "foreign" young pottery artists Zhang Jiao, Duan Mei are native of Yunnan Province. After graduating from college for the love of traditional handicrafts of ethnic minorities, to get to know the non-genetic successor Yang Shaohua master, in Yang Shaohua under the auspices of a mastermind rented a workshop, built a dragon kiln, in the Daqing on the hillside began research and production Earth pottery.

Two generations of people face the problem of handmade earth and earth, the relationship intertwined but have their own characteristics, they learn to the master, while the same as the partner to the master production orders. Two young people in the production process problems encountered in the Yang Shaohua master, by questioning and watching the process demonstration, and Yang Shaohua master of their work to make recommendations to enhance skills, this is a simple handicraft heritage, simple to regardless of their Whether it is the village people, foreigners or children, here and the Xishuangbanna Dai Autonomous Prefecture Manlun pottery and other ethnic minority areas in Yunnan ceramic transmission is a difference. This is not to say that the two young people have accepted the "tradition" of Shun Cheng. In this collision process of "biography" and "bearing", there are differences in concepts. Yang Shaohua master is a completely did not receive art education of local artisans, has been relying on the traditional market demand for single-Tao, fixed products, production methods full manual duplication, not to try to innovate and develop market audience, but also Not good at communicating with outsiders. And Zhang Jiao and Duan Mei received the art of higher education, in the study period to establish a certain aesthetic awareness, as well as the current life experience and the traditional handicraft heritage attitude. First of all, the recognition of the traditional consensus, recognizing the need for someone to learn heritage, cannot disappear because no one took over. November 21, 2015 Interview: Zhang Jiao: "or often talk to him, sometimes he will experiment it, with their methods, he did not dare to try a miscellaneous, because I think the most important people Is his aesthetic Well, right? Try out? Even if he tried out, do not know what is good-looking, what does not look good, the key is the problem, he did not aesthetic Well, for example, burned out of this thing we feel good, he That ugly dead, that is to say, even the target do not know, you try Han? Test what do not know, then you try out that feel very good, and we think not, right? "Here you can see, Differences of Two Generations' Understanding of "Aesthetics" in.

For the sale of the first to meet the traditional pottery products market, in the big Qing of the mountain to school Tao, pottery, because Zhang Jiao and Duan Mei to the traditional market as a fundamental, in Dali mainly in the traditional soil Tao products demand for Lord, on this basis, the two income issues are guaranteed, it makes the two conditions continue to pottery practice. The 
establishment of the traditional market at the same time, try to explore the province and outside the market, and a certain classification of the market, in the creation of soil Tao according to the feedback of the audience experiment. In the face of traditional markets, in their own skills and production to support the case, the two produce their own, beyond the scope of the ability to pay orders in the master Yang Shaohua production for the exploration of the market, the two networks using a circle of friends for sale, for Market development, with works to Shanghai, Changsha, Guangzhou and other cities sales and gifts, while collecting feedback. This exploration of the market and other ceramic craftsmen who are just to meet the traditional market order to create earth Tao is essentially different.

In the course of the collision, Yang Shaohua's handmade pottery and pottery art was extended. At the same time, he began to experiment with product innovation. The objection to the aesthetic awareness was discussed by exchanging with the two young people, and on the basis of functional satisfaction Increase the aesthetics of the existence of awareness, the biggest gain is the exchange of foreigners and foreign businessmen become easy and smooth. Zhang Jiao and Duan Mei in the "heritage" of this process, with Yang Shaohua master pull strings, they integrate into the local village at the same time and respect the village of Bai village harmony, have their own studio, their own dragon kiln one , In Yang Yongxing master of his two selfless teachings, understand the election mud, with mud, forming, repair blank, drying, glaze, kiln, loading kiln, burning and other traditional process, the production process errors But also the timely correction of the master Yang Shaohua, which makes the town of Fengyi traditional pottery crafts for 80 after the existence of his two continuation, and this process for his two pottery innovation, explore the market, to achieve his two contemporary pottery concept laid The basic conditions.

\section{The "organ" understanding of the "rustic" youth}

At present, in the practice of "earth apparatus", he hopes to form a cultural and creative pottery kiln area based on the fountain town Daqing hills, to form a good ceramic atmosphere and market model, and strive to carry out his two earth-Tao core concept - Simple life aesthetics. "

Two potters, in the traditional consumer groups in order to position their skills to exercise their own, then part of the rest to find Yang Shaohua and other old chefs who produced, so that one enhances the mutual "sharing", the second is to give They leave more time to practice with the earth pottery creation. This "sharing" process to maintain their contact with the traditional craftsmen, but also more clearly must thoroughly understand the entire process, only the understanding of the traditional process, the "earth pottery" materials, the overall grasp of the language in order to better Analysis of the face of the market, only in this way can be classified according to audience feedback, product positioning and innovative design.

November 21, 2015 Interview: Zhang Jiao: "We are a lot of steps to go, like this functional practical things and market requirements are very rules of these 
things, we cannot do, you can find the old master to do. In this way, this (referring to Zhang Jiao and the United States creative practice of the product), he did not want to get, he could not get out, only his pick up to do it. Here you can see, with the traditional handicrafts between the "sharing" in the process of mutual assistance and complementarity, but also be conscious of the production process in the "collaboration" division of labor to produce a classification and positioning of knowledge. Also on the basis of the production division of labor, it is possible according to non-traditional market feedback to try to product innovation, they realized that only the product innovation and rich, Jingtian Village Daqing Longtou group may increase production efficiency, Their income will be enhanced, only the increase in income, it is possible to "impress" the village had ceramic craftsmen and young migrant workers up the mountain pottery, may be so to face the traditional pottery process "inheritance" Perhaps more easily resolved.

Production and size of the increase, only Zhang Jiao and Duan Mei Feng Town, one of the expectations of the mountain, he visited the two Hunan Liling and Yunnan Red River water ceramic production areas, the purple water pottery impressed. First of all, that the purple water pottery industry model and ceramic atmosphere is very good, purple water pottery industry model worthy of their thinking, but cannot imitate, ceramic atmosphere is looking forward to, but understand the need to work with the master and all sectors of the efforts to build and perseverance.

On the Red River water purple pottery, he appreciates the local government support, appreciation of the local Red River College of personnel training and traditional craftsmen of the practice of friendship, agree with the arrival of foreign personnel to bring diversification, especially the traditional ceramic producing areas Such as the Jingdezhen pottery artists settled, local and foreign artists harmonious coexistence of the state, is conducive to the development of local crafts. On the other hand, in the Fengti town of Baizu pottery-producing areas, he and the teachers are faced with this situation is very helpless, there are ceramic enthusiasts up the mountain to watch, part of the primary and secondary school "practice" activities, and Dali University teacher with students Although the focus of the mountain increased, but are still relatively limited to the region, and "activities" due to time and space constraints, more is just "playing mud" only, graduated from Dali University Zhang Jiao and DUAN Mei 's Expectation of College Energy Value.

For the development of purple water pottery of the status quo, first of all that the water market to operate up, the potters and famous works sales "expensive", followed by more and more people will not cross-cultural pottery, that has been out of the vessel " ". Famous works become a kind of "advertised", a thousand pieces or more than a thing and consumers are not willing to buy after use, a waste of the use of the value of the vessel itself, not really into life. Other categories of artists cannot understand purple pottery craft cross-border play, calligraphy and painting calligraphy and other artists to the water purple pottery studio, directly in the ready-made body on the painting or writing, In addition to the other process by the studio to complete, the decorative angle is rich purple 
pottery visual language, on the form of no change, still with the late Qing Dynasty literati involved in purple pottery calligraphy, essentially no change, purple pottery Only with a certain master of a painting gimmick, or a master of painting and calligraphy with a purple pottery gimmick to do a "advertised" it, for the purple pottery in terms of this art is not innovative and practical significance. Perhaps the whole is moving forward, but for the future may not be a good thing, they see the understanding, but also in their own creative thinking.

Because of the "advertised" that handmade ceramic products are not really into life, the core of their practice is to make soil Tao permanent rooted life, so that ethnic minority areas originally used or not in the use of earth pottery people, to "life" To recognize the earth and Tao, so that the city has not come into contact with the people of soil and earth to a "simple beauty" perspective to accept earth pottery, so that the functional implementation, only in life with the vessel's beauty be reflected Is his two proposed "simple life aesthetics." They analyzed the prices of other artists' wood-burning utensils, positioned themselves to be not too high or too cheap, moderate, and aimed at increasing the acceptability of the audience, so that the earth-ceramic works could be cut into life, and their own ideas could be realized. November 21, 2015 interview, Zhang Jiao: "When people use this thing, it is the embodiment of aesthetics of life, this time it's the ultimate value reached, if only a few people over there to play, get a cup to sell hundreds, thousands of pieces, a little out of the value of the vessel itself, but also for the whole society is meaningless. In addition to the traditional pottery and porcelain products, he will also involve two pottery art, home improvement and public decoration works in different areas around the "life" try to practice, the purpose is to do "big", that may be such development will lead to more Many people pay attention to and participate in the production of earth and earth, "simple life aesthetics" concept easier to promote out, pottery also have fresh vitality.

\section{Conclusion}

As a "foreign" Dali outside the "craftsmanship, he is very much agree with more people, a variety of ideas involved, Zhang Jiao and Duan in the network of propaganda, while the establishment of a" Dali Taoist Society "We-Chat group, the Communication from the line to upgrade to the network, real-time, at the same time in the group to inform to share their own Long kiln, ceramics are welcome to people around the mountain "playing mud", Pottery, the real hope Fengyi region "cultural and creative soil Pottery kiln area "set up. November 21, 2015 interview: Zhang Jiao: "In short we do the things to do, after 10 years or 20 years later, the village has a family of 10 to 20 , there is a 20 to 30 young people here, the local also joined the earth to do pottery, each have their own style, each have their own feelings, the atmosphere ah $\sim$ very important, if there is such a place to develop Dali, each house has a person to reach a kind of harmonious cooperation, I think this is the most cattle.

Their understanding of pottery, in particular, sharing and inclusive, you can see for the traditional pottery inheritance is the hope that the continuation and development of the market for a certain experience, knowledge and classification 
of the traditional skills in the market to explore the development of their ceramic art is to enhance the positive and eager, and firm on the "life" of knowledge, which makes the two young people completely "rustic."

\section{References}

[1] Yunnan Provincial Local Records Compilation Committee compiled the Yunnan Provincial Local Records Compilation Committee compiled "Yunnan

Province - first volume." Yunnan People's Publishing House, 55(12), pp.68-70, 2004

[2] Information on http://www.ynxxb.com/content/2013-1/23/N35178545754 